\title{
Cancer genetics: An approach to suspected hereditary breast or colorectal cancer
}

\author{
C J Scott, MSc (Med) Genetic Counselling, PhD; M Schoeman, MSc (Med) Genetic Counselling; \\ M F Urban, BSc (Med), MB BCh, FCPaed (SA), Cert Medical Genetics (SA), PhD \\ Division of Molecular Biology and Human Genetics, Faculty of Medicine and Health Sciences, Stellenbosch University, and \\ Clinical Unit of Medical Genetics and Genetic Counselling, Tygerberg Hospital, Cape Town, South Africa
}

Corresponding author: M F Urban (urban@sun.ac.za)

Two of the most common cancers are breast cancer and colorectal cancer. Up to $10 \%$ of cases of each are associated with a high risk of recurrence in an affected individual, or of occurrence in biological relatives. This results from the presence of an underlying mutation (or 'pathogenic variant') in a high-penetrance gene. Such cases are typically associated with an autosomal dominant pattern of inheritance, although this may not be obvious in the family history. Genetic testing can identify many (but not all) of these cases, and should be offered to those whose family history or clinical features suggest a high risk. Although testing for certain risk genes (e.g. BRCA1 or BRCA2) has been available for years, the advent of next-generation sequencing 'gene panels' now allows for simultaneous testing of many more genes at lower cost. This allows for more frequent detection of pathogenic variants in underlying genes than in the past, but also makes interpretation more complex. An index of suspicion for genetic cancers and appropriate referral to a genetics health professional are increasingly important.

S Afr Med J 2019;109(4):214-218. DOI:10.7196/SAMJ.2019.v109i4.13992

Most cancers are genetic disorders, i.e. they arise from an accumulation of mutations in genes involved in biological processes such as cell cycle control and DNA repair. This accumulation results in a 'multiclonal' tumour with increasing potential for cell proliferation, invasion and metastasis. The accumulated mutations are usually somatic in origin, and are therefore limited to the tumour tissue. Genetic changes within tumours are increasingly relevant to cancer screening, prognostication, treatment and monitoring, but are not discussed in this article.

This review focuses on familial predisposition to cancer due to germline mutations. Clustering of cases of retinoblastoma provided the initial model for understanding familial cancers. Epidemiological studies suggested that retinoblastoma included a non-hereditary form and an autosomal dominant (AD) form. Knudson ${ }^{[1]}$ hypothesised that retinoblastoma required two mutational events: in the nonhereditary form both mutations occur in somatic cells, while in the $\mathrm{AD}$ form the first mutation is inherited in the germline (and therefore affects all cells), but the tumour is triggered by a 'second hit', which occurs somatically in a retinal cell.

The Knudson two-hit hypothesis explained why AD retinoblastomas occur at a younger age, and may be bilateral or multifocal. Molecular verification of the hypothesis followed after retinoblastoma was linked to mutations in the $R B 1$ gene and studies showed that carriers of a germline inactivating $R B 1$ mutation had a $90 \%$ penetrance for retinoblastoma. ${ }^{[2]}$

The development of more sophisticated genomic methods has allowed for identification of many more genes, conferring increased risk for a range of cancers. The affected genes typically have a role in control of cell replication (tumour-suppressor genes) and/or DNA repair. For the well-known genes, clinical studies have defined cancer risks better. Information about a particular gene is clinically useful if it leads to a clinical management guideline for pathogenic variants (mutations) in that gene.

The focus of the current review is on the familial predisposition of two common neoplasms: breast cancer (BC) and colorectal cancer (CRC). BC occurs in $\sim 12 \%$ of women and CRC in $\sim 4 \%$ of the general population. ${ }^{[3]}$ Familial clustering of cases of BC or CRC has long suggested a genetic basis. It is now clear that the genetics of familial BC and CRC are in principle similar to retinoblastoma, but include many more possible underlying causes. Some cases are due to co-occurrence of multiple environmental factors and low-penetrance genetic variants (and are considered multifactorial), whereas others are due to a mutation in one of several high-penetrance genes. The latter cause $10 \%$ of all cases of BC and CRC. ${ }^{[4,5]}$

Genetic testing for low-penetrance genes has low predictive value, even when combinations of genes are tested. In contrast, a positive genetic test for a moderate-to-high-penetrance gene may help refine clinical management, and allows identification of other at-risk family members who may benefit from cancer surveillance and preventive measures.

Until recently, genetic testing was limited to a few individual genes, or even more narrowly to a few pathogenic variants known to be common in certain populations. The advent of next-generation sequencing (NGS) has allowed for simultaneous sequencing of NGS multigene panels that include many genes. ${ }^{[4,5]}$ An updated approach to genetic counselling and testing for hereditary BC and CRC is discussed in light of these new gene panels.

\section{Hereditary breast cancer}

Hereditary BCs can be divided into subgroups according to the lifetime risk of $\mathrm{BC}$ that each of the individual genes confer. The high-risk genes are known to cause a lifetime risk of $\geq 40 \%$ and the moderate-risk genes cause a lifetime risk of $20-39 \% .^{[3]}$

BRCA1 and BRCA2 are the most common high-risk genes. Pathogenic variants in these genes are believed to cause $30-50 \%$ of all hereditary BCs. A pathogenic variant in one of these genes particularly predisposes to BC (lifetime risk of $39-87 \%$ ) and ovarian cancer (lifetime risk of $16-63 \%){ }^{[3]}$ The BRCA2 gene has also been associated with a smaller increased risk of certain other cancers (Table 1). 
Table 1. Hereditary breast cancer genes/syndromes that have clinical guidelines ${ }^{[2,3,6,12]}$

\begin{tabular}{|c|c|c|c|}
\hline Gene & Cancer syndrome/inheritance pattern & $\begin{array}{l}\text { Lifetime risk of female } \\
\text { BC up to } 80 \text { years, } \%\end{array}$ & $\begin{array}{l}\text { Key phenotypic features and predisposition } \\
\text { to other cancers }\end{array}$ \\
\hline$A T M$ & $\mathrm{AD}$ & $17-52$ & $\begin{array}{l}\text { Risk of BC is particularly increased } \\
(<50 \text { years of age }) \\
\text { Suspected elevated risk for pancreatic and } \\
\text { prostate cancer }\end{array}$ \\
\hline$B R C A 1$ & Hereditary $\mathrm{BC}$ and ovarian cancer syndrome/AD & $57-87$ & $\begin{array}{l}\text { Triple-negative BCs } \\
\text { High risk for ovarian cancer }(39-63 \%) \\
\text { Slightly elevated risk for male BC and } \\
\text { prostate cancer }\end{array}$ \\
\hline BRCA2 & Hereditary $\mathrm{BC}$ and ovarian cancer syndrome/AD & $38-84$ & $\begin{array}{l}\text { High risk for ovarian cancer }(16-27 \%) \\
\text { Risk of melanoma, male BC }(8.9 \%) \text {, prostate and } \\
\text { pancreatic cancer }\end{array}$ \\
\hline $\mathrm{CDH} 1$ & Hereditary diffuse gastric cancer syndrome/AD & 42 & $\begin{array}{l}\text { Lobular BC almost always co-occurs with gastric } \\
\text { cancers }(56-80 \%)\end{array}$ \\
\hline CHEK2 & $\mathrm{AD}$ & $28-39$ & $\begin{array}{l}\text { No conclusive evidence for associations with } \\
\text { other cancers, although some other cancer risks } \\
\text { suspected }\end{array}$ \\
\hline PALB2 & $\mathrm{AD}$ & $33-58$ & Later-onset $\mathrm{BC}$ and pancreatic cancer \\
\hline PTEN & $\begin{array}{l}\text { PTEN hamartoma syndromes (Cowden and } \\
\text { Bannayan-Riley-Ruvalcaba)/AD, de novo: } 11-48 \%\end{array}$ & $25-85$ & $\begin{array}{l}\text { Macrocephaly, penile freckling and fast-flow } \\
\text { vascular anomalies } \\
\text { Risk of endometrial ( } 28 \%) \text {, colorectal ( } 9 \text { - } \\
16 \%) \text {, thyroid and renal cancer, lipomas and } \\
\text { gangliocytomas }\end{array}$ \\
\hline STK11 & Peutz-Jeghers syndrome/AD, de novo: $45 \%$ & $45-50$ & $\begin{array}{l}\text { Pigmentation of lips, oral cavity and extremities, } \\
\text { but it fades after puberty } \\
\text { Early-onset BC } \\
\text { High risk for ovarian cancer ( } 18-21 \%) \\
\text { Risk of hamartomas, lung, colorectal and } \\
\text { pancreatic cancer }\end{array}$ \\
\hline TP53 & Li-Fraumeni syndrome/AD & $54-79$ & $\begin{array}{l}\text { Early-onset cancers (usually childhood or young } \\
\text { adulthood }-<30 \text { years) } \\
\text { Predisposes to all neoplasms } \\
\text { Adrenocortical carcinoma, leukaemia, brain } \\
\text { tumours, soft-tissue sarcoma, osteosarcoma BCs, } \\
\text { usually ER+, PR+ and HER2+ }\end{array}$ \\
\hline
\end{tabular}

$\mathrm{BC}=$ breast cancer; $\mathrm{AD}=$ autosomal dominant; $\mathrm{ER}$ = oestrogen receptor; $\mathrm{PR}=$ progesterone receptor; $\mathrm{HER} 2$ = human epidermal growth factor receptor 2.

Testing for pathogenic variants in the BRCA1 and BRCA2 genes has been available for more than two decades, and variants in these genes are relatively well understood. Detection of a germline genetic variant may modify treatment of a person with cancer. A family member carrying a pathogenic variant may be offered intensive screening, risk-reducing surgery or other prophylactic measures, as recommended by evidence-based international guidelines, such as the US National Comprehensive Cancer Network (NCCN) and UK National Institute for Health and Care Excellence (NICE). ${ }^{[6,7]}$

If no pathogenic variants are detected in $B R C A 1$ or $B R C A 2$, the $\mathrm{BC}$ may relate to a mutation in another gene associated with an increased risk of BC. Recent evidence suggests that other known genes account for up to $40 \%$ of cases, although this remains to be determined in local populations. ${ }^{[4]}$ The following moderate- (to high) risk genes, for which international clinical management guidelines are available, account for most of these: CHEK2, PALB2 and ATM. ${ }^{[4]}$

A small proportion $(\sim 3 \%)$ of hereditary BCs are due to genetic cancer syndromes that predispose to a broader range of cancers. These include hereditary diffuse gastric cancer syndrome, LiFraumeni syndrome, PTEN hamartoma tumour syndrome, and
Peutz-Jeghers syndrome. ${ }^{[4]}$ Further details regarding each of the genetic and syndromic causes are summarised in Table 1.

\section{Hereditary colorectal cancer}

Hereditary CRC can be phenotypically divided into two types: non-polyposis associated and polyposis associated - the latter including polyps that are either adenomas or hamartomas. The cancer phenotype has traditionally been used to guide further genetic testing. Specific well-known hereditary CRC genes and syndromes are causative of each phenotype, as summarised in Table $2 .^{\left[{ }^{5]}\right.}$

Lynch syndrome (previously referred to as hereditary nonpolypotic colorectal cancer (HNPCC) syndrome) is the most common cause of familial CRC, accounting for up to $6 \%$ of all cases. It is associated with a non-polyposis phenotype (i.e. no or few polyps detected on colonoscopy), and is caused by pathogenic variants in mismatch repair genes, e.g. $M L H 1, M S H 2$ (and the nearby EPCAM gene), MSH6 and PMS2 ${ }^{[5]}$ Individuals with a mutation in one of these genes are also susceptible to extracolonic cancers (Table 2). ${ }^{[3,5]}$

Pathogenic variants in Lynch syndrome genes cause abnormal repair of mismatches in DNA base pairs, leading to a phenomenon 
Table 2. Hereditary colorectal cancer genes/syndromes that have clinical guidelines ${ }^{[3,5,9]}$

\begin{tabular}{|c|c|c|c|c|}
\hline Gene & $\begin{array}{l}\text { Cancer syndrome/ } \\
\text { inheritance pattern }\end{array}$ & $\begin{array}{l}\text { Polyp burden } \\
\text { and type }\end{array}$ & $\begin{array}{l}\text { Lifetime risk of CRC } \\
\text { up to } 70 \text { years, \% } \\
\text { (mean age of onset, } \\
\text { years) }\end{array}$ & $\begin{array}{l}\text { Key phenotypic features and predisposition } \\
\text { to other cancers }\end{array}$ \\
\hline $\begin{array}{l}\text { MLH1 } \\
\text { MSH2 } \\
\text { MSH6 } \\
\text { PMS2 } \\
\text { EPCAM }\end{array}$ & Lynch syndrome/AD & $\begin{array}{l}<5 \\
\text { Adenoma }\end{array}$ & $35-75(27-46)$ & $\begin{array}{l}\text { Non-polyposis and usually MMR-deficient } \\
\text { High risk for endometrial cancer }(15-40 \%) \\
\text { Risk for other cancers (not in } M S H 6 \text { and } P M S 2 \\
\text { carriers): ovarian ( } 10 \text { - 15\%), small-bowel, brain, } \\
\text { pancreatic and gastric cancers }\end{array}$ \\
\hline$A P C$ & $\begin{array}{l}\text { Familial adenomatous } \\
\text { polyposis or attenuated } \\
\text { familial adenomatous } \\
\text { polyposis/AD }\end{array}$ & $\begin{array}{l}\text { FAP }>100 \\
\text { AFAP } 0-100 \\
\text { Adenoma }\end{array}$ & $\begin{array}{l}\text { FAP } 93-100(<35-40) \\
\text { AFAP } 63(54-62)\end{array}$ & $\begin{array}{l}\text { FAP: very young onset of adenomatous polyposis } \\
\text { ( } 7-36 \text { years) } \\
95 \% \text { become neoplastic (by } 35 \text { years) } \\
\text { Soft-tissue tumours, osteomas and dental anomalies } \\
\text { Risk of small-bowel cancers }(4-12 \%) \\
\text { Attenuated FAP: fewer polyps and later onset } \\
\text { (usually }>50 \text { years) }\end{array}$ \\
\hline MUTYH & $\begin{array}{l}\text { MUTYH-associated } \\
\text { polyposis/AR }\end{array}$ & $\begin{array}{l}0-100 \\
\text { Adenoma }\end{array}$ & 80 (biallelic) $(50-58)$ & $\begin{array}{l}\text { Few adenomatous polyps that seem to follow AR } \\
\text { pattern of inheritance (may be isolated case in the } \\
\text { family) } \\
\text { Risk of gastrointestinal, duodenal, endometrial and } \\
\text { thyroid cancers }\end{array}$ \\
\hline PTEN & $\begin{array}{l}\text { PTEN tumour } \\
\text { hamartoma } \\
\text { syndromes/AD }\end{array}$ & $\begin{array}{l}1-100 \\
\text { Hamartoma }\end{array}$ & $9-16(44)$ & Table 1 \\
\hline STK11 & $\begin{array}{l}\text { Peutz-Jeghers } \\
\text { syndrome/AD, } \\
\text { de novo: } 45 \%\end{array}$ & $\begin{array}{l}1-100 \\
\text { Hamartoma }\end{array}$ & $39-57(34-46)$ & Table 1 \\
\hline $\begin{array}{l}\text { SMAD4 } \\
\text { BMPR1A }\end{array}$ & $\begin{array}{l}\text { Juvenile polyposis } \\
\text { syndrome/AD }\end{array}$ & $\begin{array}{l}5 \text { - } 200 \\
\text { Hamartoma }\end{array}$ & $20-50(42-44)$ & $\begin{array}{l}\text { SMAD4-associated juvenile polyposis syndrome: } \\
\text { hereditary haemorrhagic telangiectasia } \\
\text { Risk of gastric (21\%), pancreatic and small-bowel } \\
\text { cancers }\end{array}$ \\
\hline
\end{tabular}

called 'microsatellite instability' (MSI) in tumour tissue. This is detectable with appropriate tumour DNA testing. Alternatively, tumour immunohistochemistry (IHC) may detect loss of staining for the protein products of one or more of the mismatch repair genes. Immunohistochemistry, often done together with MSI, may guide testing of the mismatch repair genes. ${ }^{[5]}$

The revised Bethesda guidelines ${ }^{[8]}$ were developed to determine if IHC and/or MSI should be performed on a CRC sample. If tumour testing is not easily accessible, the guidelines may help to determine whether an affected individual should be offered genetic testing of the mismatch repair genes. The criteria are as follows:

- CRC at $<50$ years of age

- synchronous or metachronous CRC or other Lynch-related tumours at any age

- CRC at $<60$ years of age, with tumour histology suggesting high MSI

- CRC in $\geq 1$ first-degree relative(s) with a Lynch-related tumour, 1 diagnosed at $<50$ years of age

- CRC in $\geq 2$ first- or second-degree relatives with Lynch-related tumours at any age.

The polyposis-associated syndromes are differentiated by polyp histology, the spectrum of extracolonic cancers and other clinical manifestations as detailed in Table 2. Each of these syndromes account for $<1 \%$ of all CRC cases. ${ }^{[5]}$

\section{When to suspect hereditary breast or colorectal cancer ${ }^{[6,7,9-11]}$}

If a person has a history of $\mathrm{BC}$ or $\mathrm{CRC}$, further personal and family history should be obtained. The following characteristics significantly increase the likelihood of hereditary BC or CRC, and should prompt referral to a cancer genetics professional, usually a medical geneticist or genetic counsellor:

- young age at diagnosis ( $<40$ years for BC, $<50$ years for CRC)

- bilateral or multifocal BC, or BC in a male

- CRCs or multiple colonic/endometrial polyps

- anyone with BC, ovarian or pancreatic cancer who is of Afrikaner and/or Ashkenazi Jewish ancestry

- histopathological characteristics

- triple-negative BC $(<60$ years of age)

- CRC (or endometrial or ovarian cancer) with high MSI, or IHC indicating loss of expression of mismatch repair genes

- family history (or additional findings in the affected individual)

- pattern of cancer types that suggests a specific cancer syndrome (Tables 1 and 2), e.g. BC, ovarian cancer, prostate cancer and CRC, occurring in the same side of the family

- less specific family history of BC or CRC, with at least 2 affected individuals.

\section{Genetic counselling and testing}

When offering a genetic test, pre- and post-test counselling is essential, due to the complexity of genetic information and potential 


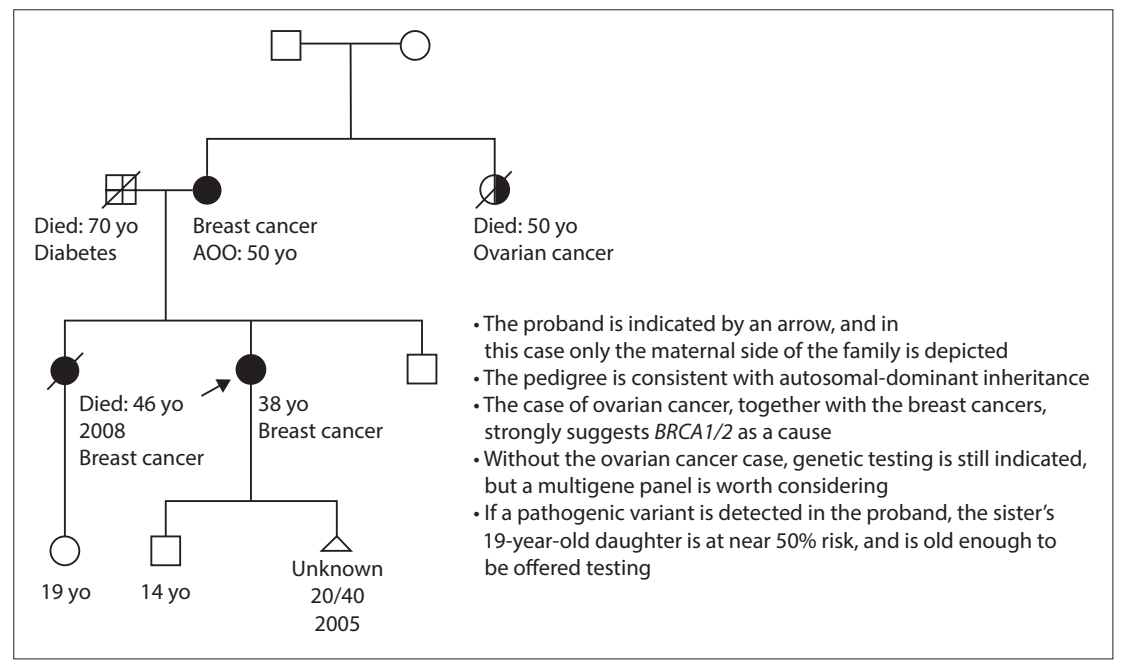

Fig. 1. Interpreting a cancer pedigree. (yo = years old; $A O O=$ age of onset.)

implications for the individual and other family members.

Pre-test genetic counselling entails a 'risk estimation' regarding the likelihood of detecting a pathogenic variant. A family history is taken and includes at least three generations and first-, second- and thirddegree relatives (Fig. 1). Cases of cancer are verified histologically if possible (more important for abdominal than breast tumours). If the likelihood of a genetic cause is high, the counsellor discusses the various genetic testing options, as well as the limitations, benefits and cost implications of each to promote informed decisionmaking. ${ }^{[10,12]}$

Patients undergoing genetic testing need to be aware of the possibility of finding a variant of uncertain significance (VUS), which has unclear health implications and does not warrant specific management. The more comprehensive the test, the more likely this finding is to occur. Screening and management should be based on the family history and other clinical risk factors, and the VUS should periodically be re-evaluated in the context of new information. ${ }^{[4,5,13]}$

If a multigene panel is offered, the possibility of a secondary finding of a pathogenic variant in a gene unrelated to the cancer being considered, needs to be discussed. The rare ethical dilemmas that may arise (as seen in the case example below) need to be kept in mind. If a secondary finding does occur, the implications and clinical management should be discussed appropriately. ${ }^{[13]}$

Given the 'actionable' nature of cancer genetic information, interest in testing is high. However, testing is more difficult if the initial consultation is with an unaffected family member. Wherever possible, genetic testing should first be performed on an affected person, as this aids interpretation of positive and negative results.

Post-test genetic counselling is provided to discuss the implications of the result, whether positive or negative, for affected individuals and other family members.

\section{Implications for an affected individual}

The finding may modify cancer treatment and/or increase risk of occurrence or recurrence of certain types of cancer. Associated risks and management should be discussed with the patient and management altered according to available clinical guidelines. In the local setting, we use a combination of the NCCN and NICE guidelines. ${ }^{[6,7,9,11]}$

If a pathogenic variant is identified, the discussion of risk should include consideration of both the variant and the family history, which may have a modifying effect. ${ }^{[4]}$

A negative genetic test should be discussed in the context of the specific test and the family history. Even the most extensive test does not necessarily preclude the presence of hereditary cancer. ${ }^{[10,12]}$

\section{Implications for family members/ children}

If a pathogenic variant is identified, there is up to a $50 \%$ chance of it being passed to a child. The patient's siblings and extended family members are also at risk. Cascade testing to identify other carriers of the variant is important, as the carriers may qualify for specific surveillance and riskreducing options. ${ }^{[6,7,9-11]}$

For genes associated with cancer in adulthood only, at-risk family members should be offered testing only when $>18$ years of age, when they are mature enough to make their own decisions. For earlier-onset conditions or in affected individuals, genetic testing is offered at a younger age..$^{[12,14]}$

Carriers of a pathogenic variant in certain genes are also at an increased risk of having children with specific severe autosomal recessive conditions, if their partner carries a variant in the same gene. ${ }^{[4]}$ Testing of partners may therefore require consideration.

\section{Case - example}

Patient X, a 28-year-old man, was referred to the genetics division because of a diagnosis of early-onset CRC at the age of 23 years. His family history indicated that his mother was adopted and his father died from bonemarrow cancer at a young age. There was no other known history of cancer. Based on the limited information available, a multigene panel for inherited cancer predisposition was requested and after pre-test counselling, the patient gave informed consent.

The results indicated a secondary finding, i.e. a pathogenic variant in the NBN gene. This gene is important in the repair of double-stranded breaks in DNA, and loss of function increases risks of certain cancers. However, it is unclear whether it significantly increases the risk of CRC. Nonetheless, it is well established that women with an NBN pathogenic variant have an up to $30 \%$ lifetime risk of $\mathrm{BC}$, and guidelines recommend more intensive screening of carrier women. Certain studies have suggested an increased risk for other cancers; however, evidence is limited and management guidelines do not exist. Using current knowledge, this information was discussed with the patient and testing was offered to at-risk female family members.

This result would not have been detected with a more limited genetic test. This information was useful in identifying females at increased risk of $\mathrm{BC}$ and informing them of the need for screening from a younger age. This should be balanced against the fact that it did not alter management in the proband, and that determination of an appropriate course of action required considerable time and attention from the clinical genetics team.

Where possible, pre-test counselling with regard to all possible scenarios and anticipated outcomes should be done to avoid such scenarios going forward.

\section{Deciding between genetic testing options (single gene v. panel)}

When offering genetic testing, a genetics professional considers personal and familial characteristics, as well as technical and economic factors (Fig. 2) ${ }^{[12,14]}$ 


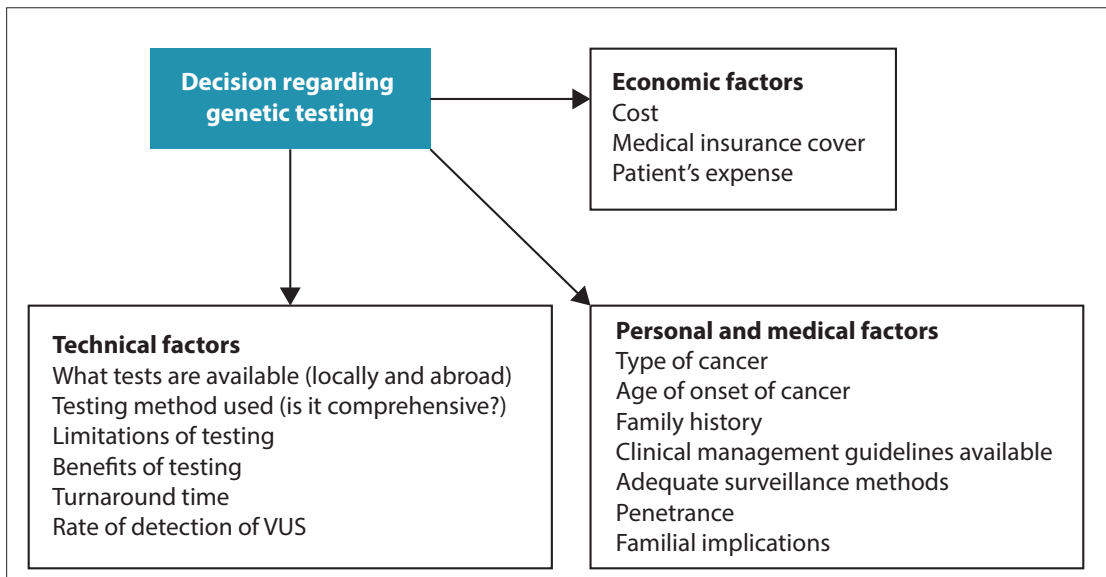

Fig. 2. Factors influencing choice of genomic test. (VUS = variant of uncertain significance.)

In South Africa (SA), availability and cost are important determinants of access to genetic tests in the state and private sectors. The National Health Laboratory Service currently provides a very limited bouquet of tests. Medical insurance companies rarely reimburse genetic testing in the private sector.

In some situations, it is reasonable first to test for founder mutations in the BRCA1, $B R C A 2$ or $M L H 1$ and $M S H 2$ genes that are common in specific SA populations. These tests are relatively cheap (ZAR1 500 3000 ), but are population specific and do not exclude all pathogenic variants.

Comprehensive testing is available locally for certain genes, especially $B R C A 1 / 2$ and the Lynch syndrome genes, and typically cost ZAR6 000 - 12000.

Broader NGS gene panels, between 10 and 100 genes, are increasingly available in laboratories based in SA and internationally. The cost may be no different to sequencing a single gene, i.e. the choice of test relates increasingly to patient and provider preference. In $\mathrm{BC}$, first-line testing with a multigene panel is increasingly considered if the features do not strongly point to BRCA1/2. In CRC, use of a multigene panel index of suspicion for genetic cancers and appropriate referral to a genetics health professional are increasingly important.

Declaration. None.

Acknowledgements. We acknowledge C Engelbrecht for her assistance in presenting the case example in this article.

Author contributions. All authors contributed equally to the article.

Funding. None.

Conflicts of interest. None.

1. Knudson AG. Mutation and cancer: Statistical study of retinoblastoma. Proc Nat Acad Sci 1971;68(4):820-823. https:// doi.org/10.1073/pnas.68.4.820

2. Cavenee WK, Dryja TP, Phillips RA, et al. Expression of recessive alleles by chromosomal mechanisms in retinoblastoma. Nature 1983;305(5937):779-784. https://doi.org/10.1038/305779a0

3. Firth HV, Hurst JA. Oxford Desk Reference: Clinical Genetics and Genomics. 2nd ed. Oxford, UK: Oxford University Press, 2017.

is not always contingent on phenotyping results, as phenotyping is only useful for a subset of genes (MSI, IHC).

Some difficulties with multigene panels have already been mentioned above, including the increased frequency of VUS and secondary findings, and the difficulty related to findings in genes lacking an established clinical management protocol. ${ }^{[6,9,13]}$ Furthermore, genomic approaches are rapidly evolving, and the relevant genes and variants remain incompletely understood - especially in less-studied African populations. Therefore, a negative test is not definitive, and may warrant consideration for future repeat testing or further research.

\section{Conclusion}

Up to $10 \%$ of BCs and CRCs are due to a single high-penetrance mutation in a family, with about half of these in the BRCA1/2 and Lynch syndrome genes, respectively. The increased availability of multigene panels allows testing of other genes, but increases the complexity of the information obtained. Detection of a genetic cause often modifies management of individuals with cancer, and is important to establish the risks for unaffected family members. Therefore, an

4. O'Leary E, Iacoboni D, Holle J, et al. Expanded gene panel use for women with breast cancer: Identification and intervention beyond breast cancer risk. Ann Surg Oncol 2017;24(10):3060-
3066. https://doi.org/10.1245/510434-017-5963-7

5. Lorans M, Dow E, Macrae FA, Winship IM, Buchanan DD. 5. Lorans M, Dow E, Macrae FA, Winship IM, Buchanan DD.
Update on hereditary colorectal cancer: Improving the clinical utility of multigene panel testing. Clin Colorect Cancer 2018;17(2):e293-e305. https://doi.org/10.1016/j.clcc.2018.01.001

6. National Comprehensive Cancer Network. Genetic/ familial high-risk assessment: Breast and ovarian. Version 1. 2018. www2. trikobe.org/nccn/guideline/gynecological/english/genetic_ familial.pdf (accessed 10 July 2018).

7. National Institute for Health and Care Excellence. Familial breast cancer: Classification, care and managing breast cancer and related risks in people with a family history of breast cancer. 2016. www.nice.org.uk/guidance/cg164 (accessed 22 February 2019).

8. Umar A, Boland CR, Terdiman JP, et al. Revised Bethes . Umar A, Boland CR, Terdiman JP, et al. Revised Bethesda guidelines for hereditary non-polyposis colorectal cancer (Lynch syndrome) and microsatellite instability. J Natl Cancer Inst
2004;96(4):261-268. 9. $2004 ; 96(4): 261-268$

9. Gupta S, Provenzale D, Regenbogen SE, et al. NCCN guidelines insights: Genetic/familial high-risk assessment: colorectal. J Natl Compr Cancer Netw 2017;15(12):1465-1475. https://doi org/10.6004/jnccn.2017.0176

10. Loubser F, Edge J, Fieggen K. Epidemiology, risk factors and genetics of breast cancer. CME 2008;26(10):497-500.

11. National Institute for Health and Care Excellence. Colorectal cancer: Diagnosis and management. 2016. www.nice.org.uk/ guidance/cg131 (accessed 22 February 2019).

12. Gericke G, Walters S. BRCA gene testing: A general overview. Pathchat 2013;(10). www.ampath.co.za/wp-content/ newupload/2014/11/pathchat_10-BRCA-gene-testing.pdf (accessed 10 July 2018)

13. Van Marcke C, de Leener A, Berliere M, Vikkula M, Duhoux FP. Routine use of gene panel testing in hereditary breast cancer should be performed with caution. Crit Rev Oncol Hemato 2016;108:33-39. https://doi.org/10.1016/j.critrevonc.2016.10.008

14. Okur V, Chung WK. The impact of hereditary gene panels on clinical care and lessons learned. Cold Spring Harbor Mol Case Stud 2017;3(6):pii.a002154. https://doi.org/10.1101/mcs.a002154

Accepted 20 February 2019. 